\title{
Atualzaçäo EM DIAGNÓStico dA OTITE MÉdia AGUdA NA INFÂNCIA, BASEADA EM EVIDÊNCIAS E CENTRADA NO PACIENTE
}

\author{
Eulália Sakano; Luc L. M. Weckx; Moacyr Saffer; Wanderley Marques Bernardo
}

\section{TEMA ABORDADO}

Especialidade de abrangência: Otorrinolaringologia e Pediatria

Diretriz a ser consultada: Diagnóstico da otite média aguda na infância

\section{Cenários e Questões clínicas}

I. Na otite média aguda (OMA), como diferenciar, pelos sintomas e sinais, infecção bacteriana de viral? Em relação a esta questão é falso afirmar que:

a - A probabilidade do diagnóstico de OMA em crianças menores de 4 anos, com infecção de vias aéreas superiores (IVAS), associada a dor de ouvido, é 7,5 vezes maior do que na ausência de dor.

b - Os casos com cultura positiva têm sinais e sintomas significativamente mais severos do que os casos com cultura negativa. c - O abaulamento e a hiperemia de membrana timpânica (MT) são os dois sinais mais importantes no diagnóstico diferencial com cultura negativa.

d-A presença de miringite bolhosa define etiologia viral.

2. Quanto à etiologia da OMA por S Pneumoniae, é falso afirmar que:

a - A contagem sangüínea de leucócitos total e de neutrófilos é significativamente maior nos casos de cultura negativa, do que naqueles de $S$ Pneumoniae.

b - A probabilidade de etiologia por $S$ Pneumoniae quando na presença de alterações severas na membrana timpânica é 5,8 vezes maior.

c - A probabilidade de etiologia por $S$ Pneumoniae quando na presença de dor de ouvido e temperatura retal (Tret) $=38^{\circ} \mathrm{C}$ é 3 vezes maior.

d-A probabilidade de etiologia por $S$ Pneumoniae quando na presença de alterações severas na membrana timpânica e Tret $=38^{\circ} \mathrm{C}$, no verão, é 5 vezes maior.

3. Em relação à etiologia da OMA por $\boldsymbol{H}$ Influenza, é falso afirmar que:

a - Os casos de $H$ Influenza têm sinais e sintomas significativamente mais severos do que os casos com cultura negativa. b - A probabilidade de etiologia por $H$ Influenza quando na presença de conjuntivite purulenta é 9,5 vezes maior.

c-A probabilidade de etiologia por $H$ Influenza quando na presença de conjuntivite purulenta, e com história prévia de OMA, é 13 vezes maior.

d-A contagem de neutrófilos é significativamente maior nos casos de cultura negativa do que naqueles de $H$ Influenza.

\section{Quais aspectos otoscópicos sugerem OMA? Qual a} contribuição da timpanometria na OMA?

a - Na presença de abaulamento da membrana timpânica (MT), a probabilidade de a criança ter OMA é 5 I vezes maior do que não ter (IC 95\%: 36-73).

b- Na presença de cor opaca da MT, a probabilidade de a criança ter OMA é 34 vezes maior (IC 95\%: 28-42).

c - A timpanometria aumenta em $20 \%$ a $30 \%$ a quantidade de OMA diagnosticadas.

d- O pico de pressão timpanométrico (PPT) negativo $(<-100)$, em criança menor de 2 anos, sugere infecção viral (OR: 4,I, para cultura negativa).

\section{Resposta da Atualização em Diagnóstico de Doenças da Tireóide} (Publicado na RAMB 2006; 52(2): ?)

I - A dosagem de T3 também tem boa acurácia no diagnóstico do hipotireoidismo, principalmente na fase inicial, auxiliando na definição do diagnóstico (alternativa "c").

2 - Fisiologicamente, o hiperestrogenismo gestacional leva a uma diminuição dos níveis de globulina ligadora de tiroxina (TBG) e, conseqüentemente, diminuição nos níveis de T4 e T3 totais, podendo confundir a situação com hipotireoidismo (alternativa "d").

3 - Paciente com bócio uninodular. Exames mostram TSH <0,0 I mU/ml, T4 livre 2,I ng/dl, T3 358 ng/dl, TRAB 8\% de inibição, ATPO $21 \mathrm{U} / \mathrm{ml}$; cintilografia mostra nódulo único em lobo esquerdo, assumindo o funcionamento da tireóide. Pode-se tratar de Doença de Graves, pois cerca de 5\% a 10\% dos portadores têm TRAB e ATPO negativos (alternativa "c").

4 - Paciente de 27 anos, sexo feminino, com diagnóstico estabelecido de Doença de Graves há 4 meses, em uso de Propiltiouracil (PTU). Clinicamente em eutiroidismo, TSH 0, Im/L (ref 0,5-4,5), T4 livre I,4ng/dl (ref 0,8- I,8), T3 170 ng/dl (ref 80-190). Deve-se aumentar a dose do PTU, pois o TSH sozinho é o melhor parâmetro no acompanhamento do tratamento do hipertiroidismo, já que este não demora muito para se normalizar (alternativa "c"). 